Effects of microst ruct ures on fat i gue behavi or of an $\mathrm{Al}-\mathrm{MS}$ - Sc al I oy at an el evated t emper at ur $\mathrm{e}$

\begin{tabular}{|l|l|}
\hline 著者 & Wat anabe Chi hi ro, Monzen Ryoi chi \\
\hline $\begin{array}{l}\text { j our nal or } \\
\text { publ i cat i on t i t l e }\end{array}$ & Nat er i al s Sci ence For um \\
\hline vol une & $706-709$ \\
\hline page range & $426-430$ \\
\hline year & 2012-01-01 \\
\hline URL & ht t p: //hdl . handl e. net /2297/30361 \\
\hline
\end{tabular}

doi: 10.4028/www.scientific.net/MSF.706-709.426 


\title{
Effects of microstructures on fatigue behavior of an Al-Mg-Sc alloy at an elevated temperature
}

\author{
Chihiro Watanabe ${ }^{1, a}$, and Ryoichi Monzen ${ }^{1, b}$ \\ ${ }^{1}$ Division of Innovative Technology and Science, Kanazawa University, Kakuma-machi, Kanazawa \\ 920-1192, Ishikawa, Japan \\ achihiro@t.kanazawa-u.ac.jp, ${ }^{\mathrm{b}}$ monzen@t.kanazawa-u.ac.jp
}

Keywords: Al-Mg-Sc alloy, Fatigue, Dislocation structure, Precipitation free zone

\begin{abstract}
Polycrystalline Al-1wt\%Mg-0.27wt\%Sc alloys bearing $\mathrm{Al}_{3} \mathrm{Sc}$ particles with different average sizes of 4 and $11 \mathrm{~nm}$ in diameter have been cyclically deformed at $423 \mathrm{~K}$ under various constant stress amplitudes, and the relationship between fatigue characteristics and microstructure of the alloy has been investigated. The specimen bearing $11 \mathrm{~nm}$ particles exhibited a cyclic hardening to saturation, while in specimens with the small particles a cyclic softening was observed after initial hardening. In the specimen with large particles, dislocations were uniformly distributed under all applied stress amplitudes, whereas the specimens bearing small particles, in which cyclic softening occurred exhibited clearly developed slip bands. The cyclic softening for the latter specimen was explained by particle shearing within the strongly strained slip bands. The width of precipitate free zones (PFZs) has been found to be one of the factors affecting the fatigue life of the specimens at 423K. The two-step aging decreases the width of PFZs, resulting in increase in the fatigue life.
\end{abstract}

\section{Introduction}

Aluminum alloys with magnesium as the major alloying element constitute a group of non heat-treatable alloys with medium strength, high ductility, excellent corrosion resistance and weldability. Unfortunately, the strength of such Al-Mg alloys is lower than precipitation-hardening $\mathrm{Al}$ alloys. However, the addition of a small amount of scandium has been found to significantly improve the strength of Al-Mg alloys [1-3], owing to the presence of coherent, finely dispersed $\mathrm{L}_{2}$ $\mathrm{Al}_{3} \mathrm{Sc}$ precipitate particles that can be obtained at a high number density, thus preventing the dislocation motion. Also the $\mathrm{Al}_{3} \mathrm{Sc}$ particles have modest coarsening rates at elevated temperatures, leading to the effective suppression of recrystallization and the stabilization of microstructures at high temperatures. Thus Sc-containing Al-Mg alloys are expected to be used in higher-temperature application compared to conventional structural Al alloys.

In previous study [4], we examined the cyclic deformation behavior and dislocation microstructure under plastic-strain-controlled conditions at $423 \mathrm{~K}$, using an aged Al-Mg-Sc alloy with $\mathrm{Al}_{3}$ Sc particles of different diameters, i.e. 4, 6 and $11 \mathrm{~nm}$, which correspond to under-age, peak-age and over-age conditions, respectively. The over-aged alloy showed cyclic hardening to saturation. On the other hand, cyclic softening occurred in the under-aged and peak-aged alloys. Transmission electron microscopy (TEM) observation revealed that the 6 and $11 \mathrm{~nm} \mathrm{Al} \mathrm{Al}_{3} \mathrm{Sc}$ particles have a stronger retardation effect on the formation of fatigue-induced stable dislocation structure than $4 \mathrm{~nm}$ particles at $423 \mathrm{~K}$.

To establish a multifunctional method for fatigue life assessments, it is very useful to know the similarities and differences between stress- and strain-controlled fatigue behaviors. In this study, a polycrystalline Al-Mg-Sc alloy with dispersed $\mathrm{Al}_{3} \mathrm{Sc}$ particles is cyclically deformed at an elevated temperature of $423 \mathrm{~K}$ under various constant stress amplitudes, and the dislocation structure is investigated in relation to the stress-strain responses. As in the previous study [4], the two particle diameters of 4 and $11 \mathrm{~nm}$ have been selected.

\section{Experimental procedure}


Specimens for fatigue tests were cut from hot-rolled polycrystalline Al-1mass\%Mg- $0.27 \mathrm{mass} \% \mathrm{Sc}$ alloy plates with the stress axis parallel to the rolling direction. These specimens were solutionized at $905 \mathrm{~K}$ for $7.2 \times 10^{3} \mathrm{~s}$ and water quenched. TEM observations revealed that no precipitates existed in the solution treated specimens. To obtain spherical and coherent $\mathrm{Al}_{3} \mathrm{Sc}$ particles, one set of solutionized specimens was aged at $573 \mathrm{~K}$ for $9.0 \times 10^{2} \mathrm{~s}$, and second set was aged at $623 \mathrm{~K}$ for 6.48 $\mathrm{x} 10^{4} \mathrm{~s}$, corresponding to under-aging and over-aging conditions which produced almost the same Vickers hardness of 70. Hereafter, these under-aged and over-aged specimens will be referred to as specimens UA and $\mathrm{OA}$, respectively. The average diameter of $\mathrm{Al}_{3} \mathrm{Sc}$ particles in specimens UA was 4 $\mathrm{nm}$, while the particle diameter in specimen OA averaged $11 \mathrm{~nm}$. The average size was determined from TEM observations of over 200 particles. In addition another set of solution-treated specimens underwent a two-step aging treatment, that is, aging at $573 \mathrm{~K}$ for $3.0 \times 10^{2}$, water quenching, and then aging at $623 \mathrm{~K}$ for $6.48 \times 10^{4} \mathrm{~s}$. This two-step aging produced $\mathrm{Al}_{3} \mathrm{Sc}$ particles with the same diameter of $11 \mathrm{~nm}$. The two-step-aged specimen will be referred to as specimen OA2. Judging from the Al-Sc equilibrium phase diagram [5], the volume fractions of the $\mathrm{Al}_{3} \mathrm{Sc}$ particles in specimens UA, OA and OA2 are nearly identical and are estimated as 0.007 .

All mechanical tests were carried out at $423 \mathrm{~K}$ in air. Tensile properties were determined with an initial strain rate of $3.0 \times 10^{-3} \mathrm{~s}^{-1}$. Fully-reversed tension-compression fatigue tests were performed under stress-amplitude control. The ramp loading method [6] was adopted and the ramp loading length was set to 30 cycles. A low frequency of $0.5 \mathrm{~Hz}$ was employed when the tests were started and the frequency was increased up to $10 \mathrm{~Hz}$ after several tens of cycles. The stress-strain hysteresis loops were monitored with a digital oscilloscope.

The fatigued specimens were sliced into 3mm disks parallel to the stress axis and were mechanically ground down to $0.2 \mathrm{~mm}$. Thin foils for TEM observations were prepared by electro-polishing. Microscopy was performed with JOEL-2000EX and JOEL-2010FEF microscopes operating at $200 \mathrm{kV}$.

\section{Results and Discussion}

Mechanical Properties. The solutionized and aged specimens were coarse-grained with an equiaxed grain size of 0.5 to $1 \mathrm{~mm}$. The Al-Mg-Sc ternary equilibrium phase diagram [7] shows that $\mathrm{Mg}$ in the present Al-1mass\%Mg-0.27mass\%Sc alloy does not form any compounds at the aging temperatures examined. In fact, aging of the alloy at 573 and $623 \mathrm{~K}$ produced only spherical $\mathrm{Al}_{3} \mathrm{Sc}$ particles in the Al matrix.

Table 1 summarizes the tensile properties of specimens UA and OA tested at $423 \mathrm{~K}$. For comparison, the results obtained at RT are also indicated. At $423 \mathrm{~K}$, the values of $0.2 \%$ proof stress of the specimens UA and OA are almost the same. The values of $0.2 \%$ proof stress and tensile stress of both the specimens are smaller than those obtained at RT, while the values of fracture strain of specimens show a reverse tendency.

Table 1 Tensile properties of specimens UA, OA and OA2 obtained at 423 $\mathrm{K}$ and room temperature (RT).

\begin{tabular}{|c|c|c|c|c|c|c|}
\hline \multirow[t]{2}{*}{ Specimen } & \multicolumn{2}{|c|}{$\begin{array}{c}0.2 \% \text { proof } \\
\text { stress } \\
\text { (MPa) }\end{array}$} & \multicolumn{2}{|c|}{$\begin{array}{l}\text { Tensile } \\
\text { stress } \\
\text { (MPa) }\end{array}$} & \multicolumn{2}{|c|}{$\begin{array}{l}\text { Fracture } \\
\text { elongation } \\
(\%)\end{array}$} \\
\hline & $423 \mathrm{~K}$ & RT & $423 \mathrm{~K}$ & $\mathrm{RT}$ & $423 \mathrm{~K}$ & RT \\
\hline UA & 127 & 130 & 150 & 170 & 24 & 21 \\
\hline OA & 121 & 125 & 147 & 174 & 27 & 21 \\
\hline OA2 & 118 & 125 & 143 & 172 & 29 & 24 \\
\hline
\end{tabular}

Fatigue tests under stress-amplitude control were performed at $423 \mathrm{~K}$ under stress amplitude control condition. The cyclic-deformation curves of specimens OA and UA are shown in Figs. 1 (a) 
and (b), where the plastic strain amplitude $\varepsilon_{\mathrm{pl}}$ is plotted against the number of fatigue cycles $(N)$. In the case of stress-controlled tests, the decrease of $\varepsilon_{\mathrm{pl}}$ against $N$ means cyclic hardening, and the increase of $\varepsilon_{\mathrm{pl}}$ corresponds to cyclic softening. For comparison, the cyclic-deformation curves for specimens OA and UA obtained at RT are also indicated in Figs. 1 [8].

In the OA specimens, monotonic hardening can be seen. The $\varepsilon_{\mathrm{pl}}$ decreases rapidly with increasing $N$ and finally reaches saturation at all applied stress amplitudes. In contrast, the cyclic deformation curves of specimens UA show initial hardening and then clear cyclic softening at all stress amplitudes. No crack was detected on the specimen surface, indicating that the cyclic softening in specimens UA is not caused by surface crack initiation. The difference in the fatigue behavior between the specimens $\mathrm{OA}$ and UA will be discussed bellow in terms of the difference in the size of the $\mathrm{Al}_{3} \mathrm{Sc}$ particles.
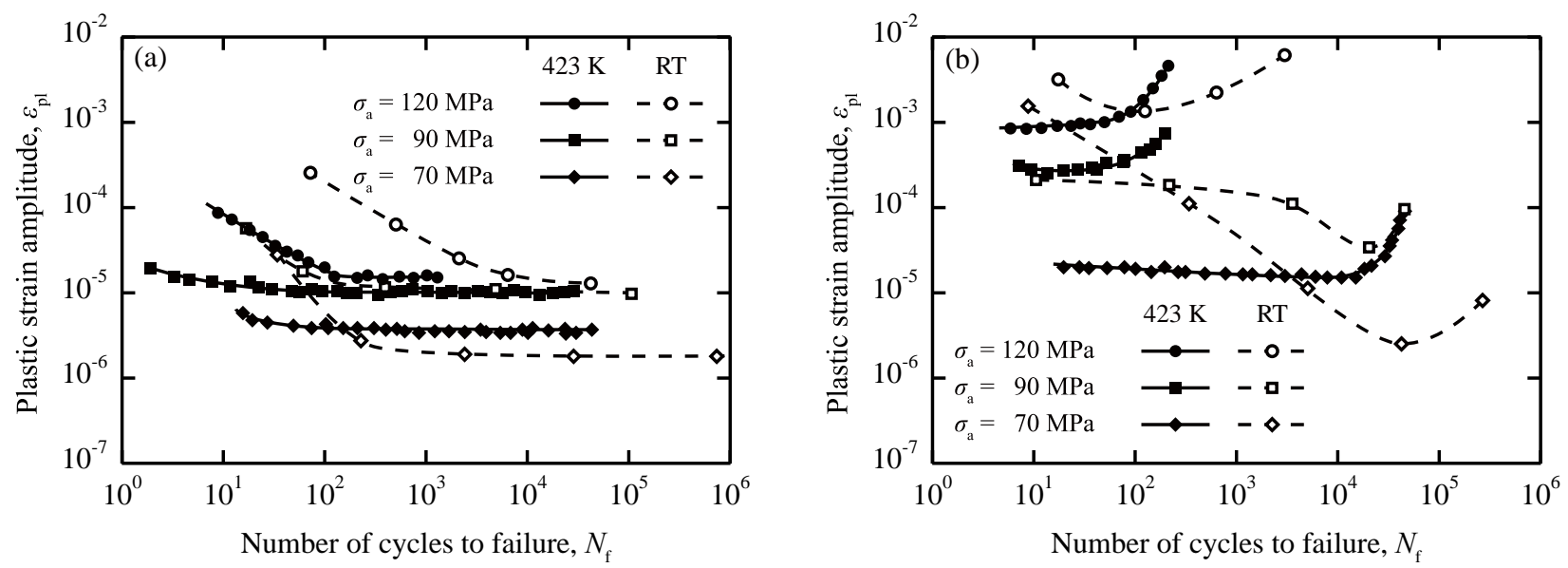

Fig. 1 Cyclic-deformation curves of specimens (a) OA and (b) UA obtained under various stress amplitudes $\sigma_{\mathrm{a}}$. Also shown are the results obtained at RT [8].
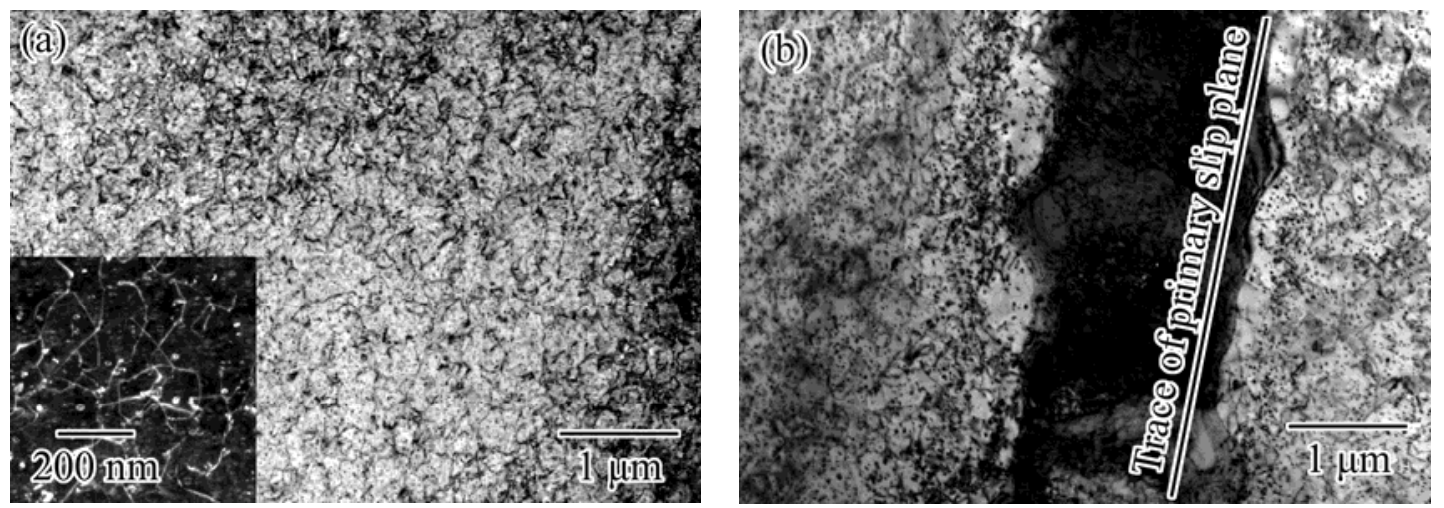

Fig. 2 TEM micrographs of specimens (a) OA and (b) UA fatigued under $\sigma_{\mathrm{a}}=90 \mathrm{MPa}$. The inset in (a) is enlarged dark-field image.

Microstructures. Figures 2 (a) and (b) depict the typical fatigue dislocation microstructures formed at $423 \mathrm{~K}$ under a applied stress amplitude $\sigma_{\mathrm{a}}$ of $90 \mathrm{MPa}$ for specimens OA and UA. In the specimen OA, dislocations were uniformly distributed under all applied stress amplitudes, whereas the specimen UA, in which cyclic softening occurred in Fig. 1(b), exhibited clearly developed slip bands along the trace of primary slip plane. These slip bands indicate the occurrence of very inhomogeneous deformation. In other words, strong strain localization took place within the slip bands. Such strong strain localization usually causes the destruction and re-dissolution of particles [9]. To check whether shearing of $\mathrm{Al}_{3}$ Sc particles occurred during fatigue tests at $423 \mathrm{~K}$, the average size of the $\mathrm{Al}_{3} \mathrm{Sc}$ particles within slip bands or in the matrix was measured by TEM using a specimen UA re-aged at $623 \mathrm{~K}$ for $6.48 \times 10^{4} \mathrm{~s}$ following a fatigue test to failure. The resulting average diameters were about $9 \mathrm{~nm}$ within the slip bands and $12 \mathrm{~nm}$ in the matrix. This discrepancy in the particle size implies that the small $\mathrm{Al}_{3} \mathrm{Sc}$ particles of $4 \mathrm{~nm}$ were cut by moving dislocation within the strongly 
strained slip bands. The cyclic softening in specimen UA in fig. 1 (b) can then be explained by a decrease in particle strengthening through particle shearing or re-dissolution within the slip bands.

Fatigue Life. The results of fatigue life tests ( $S$ - $N$ curves) for specimens UA and OA are shown in Fig. 3, where $\sigma_{\mathrm{a}}$ is plotted as a function of the number of cycles to failure $\left(N_{\mathrm{f}}\right)$. Since slip bands are known as sites for crack initiation, as would be expected, the specimen OA shows more enhanced fatigue life than the specimen UA.

In the specimen OA, precipitate-free zones (PFZs) were formed near the grain boundaries, and the averaged PFZs width was about $200 \mathrm{~nm}$. In the addition to the difference in $\mathrm{Al}_{3} \mathrm{Sc}$ particle sizes as mentioned above, the existence of PFZs can be pointed out as another factor affecting fatigue life. These PFZs have a low yield

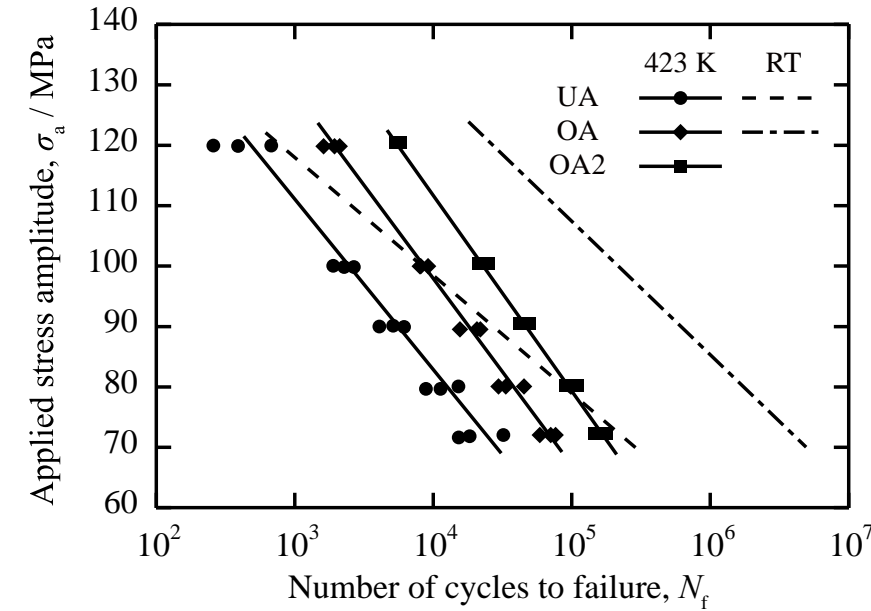

Fig. $3 S-N$ curves for specimens OA, UA and OA2 obtained at $423 \mathrm{~K}$. The results for specimens OA and UA obtained at RT are also indicated [8]. stress in comparison with the grain interior, thus favoring dislocation movement, and eventually crack nucleation seems to occur within the PFZs. In fact, the macroscopic cracks nucleated and propagated predominantly along the grain boundaries in the specimen OA, but the crack nucleation in the specimen UA occurred almost exclusively along the slip bands. Thus, It can be said that the existence of PFZs has a detrimental influence on the fatigue life of specimen OA.

The tensile properties of specimen OA2, two-step aged at $573 \mathrm{~K}$ for $3.0 \times 10^{2}$ s and then at $423 \mathrm{~K}$ for $6.48 \times 10^{4} \mathrm{~s}$, are summarized in Table 1 . The two-step aging did not essentially change the $\mathrm{Al}_{3} \mathrm{Sc}$ particles size and the strength but does increases the elongation. Also, the width of PFZs was reduced from $200 \mathrm{~nm}$ to $110 \mathrm{~nm}$ by the two-step aging. Comparison between the $S$ - $N$ curves of specimens OA and OA2 in Fig. 3 shows that the two-step aging results in enhanced fatigue life. Therefore we conclude that the decrease in the PFZ width brings about the increase in the fatigue life.

\section{Summary}

Stress amplitude controlled fatigue tests of Al-Mg-Sc alloy polycrystals with $\mathrm{Al}_{3} \mathrm{Sc}$ particles of 4 and $11 \mathrm{~nm}$ in diameter were performed at $423 \mathrm{~K}$. The results and conclusions are summarized as follows.

(1) Specimens UA bearing $4 \mathrm{~nm} \mathrm{Al}_{3}$ Sc particles show cyclic softening, while specimen OA with $11 \mathrm{~nm} \mathrm{Al}$ Sc particles show cyclic hardening to saturation.

(2) In the specimens UA, slip band dislocation structures are observed, and, in the specimen OA, dislocations are uniformly distributed.

(3) The cyclic softening of specimen UA is caused by shearing of small $\mathrm{Al}_{3} \mathrm{Sc}$ particles within the slip bands.

(5) Two-step aging brings about reduction in the width of precipitate-free zones in the specimen with large particles and, as a result, it enhanced the fatigue life of the specimen.

\section{Acknowledgement}

This work was financially supported in part by The Light Metal Educational Foundation, Inc. The authors wish to acknowledge Furukawa SKY Aluminum Ltd. for supplying the alloys.

\section{References}


[1] M. Y. Drits, L. B. Ber, Y. G. Bykov, L. S. Toropova, G. K. Anastaseva, Aging of Al-0.3at.\%Sc alloy, Phys. Met. Metall, 57 (1984) 118-126.

[2] R. R. Sawtell, C. L. Jensen, Mechanical properties and microstructures of Al-Mg-Sc alloys, Metall. Mater. Trans. A, 21 (1990) 421-430.

[3] V. I. Elagin, V. V. Zakharov, T. D. Rostova, Scandium-alloyed aluminum alloys, Met. Sci. Heat Treat., 34 (1992) 37-45.

[4] C. Watanabe, R. Monzen, Fatigue behavior and microstructure of an Al-Mg-Sc alloy at an elevated temperature, J. Physics: Conf. Series, 240 (2010) 012049.

[5] J. L. Murray, The Al-Sc (aluminum-scandium) system, J. Phase Equilib., 19 (1998) 380-384.

[6] L. Llanes, C. Laird, Substructure evolution of copper polycrystals under different testing conditions: conventional strain control and ramp loading, Mater. Sci. Eng. A, 161 (1993) 1-12.

[7] P. Villars, A. Prince, H. Okamoto, Handbook of ternary alloy phase diagrams, ASM, Materials Park, 1995, pp. 3900-3902.

[8] C. Watanabe, R. Monzen, K. Tazaki, Effects of $\mathrm{Al}_{3}$ Sc particle size and precipitate-free zones on fatigue behavior and dislocation structure of an aged Al-Mg-Sc alloy, Int. J. Fatigue, 30 (2008), 635-641.

[9] C. Calabrese, C. Laird, Cyclic stress - strain response of two-phase alloys Part I. Microstructures containing particles penetrable by dislocations, Mater. Sci. Eng. 13 (1974) 141-157. 